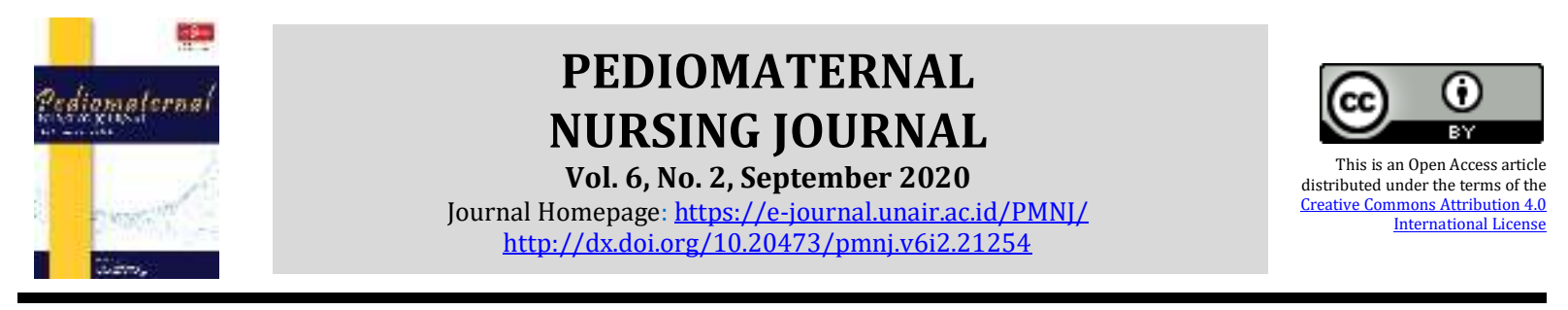

Scientific Editorial

\title{
EDITORIAL
}

\section{Raising the Value of Care to Vulnerable Population}

\author{
Joel Rey U Acob, DNsg Sc., RN \\ Dean of Nursing, Visayas State University Visca, City of Baybay, Leyte Philippines, \\ phone: +63 9569161146, email: joel.acob@vsu.edu.ph
}

With the prevailing global predicament, those populations, especially children and pregnant women, become vulnerable. Along with the uncertain future, health systems are tested to adhere to its promise of continuing the delivery of care primarily to these susceptible communities. COVID19 pandemic does not only bring a threat to health. It also offers an opportunity to ponder the extent of institutional preparedness. Attaining even and ethically practical delivery of health in these trying times means doubling efforts that call for critical thinkers and navigate possibilities in addressing the maternal and child care concerns.

Even before the new normal, concerns about the shortage of primary care workers are noticeable. The nation's system of primal care is broken, the victim of underinvestment, misaligned incentives, and malign neglect. Common preventable illnesses in early childhood years are sometimes overlooked. Therefore the severity of health condition progresses beyond uncontrollable levels. For pregnant and breastfeeding mothers, issues of malnutrition, which resulted in delayed child development, are associated with poverty and deprivation of resources. It is on this note that national leaders should spend eyes reviewing the current agenda, which interests the health of the general public.

The era of pandemic underscores raising the integrity of care to the defenseless population. The year 2020 is not the year our nursing education leaders envisioned, many of their plans have been turned upside down, and there is still change and uncertainty ahead. Nursing scholars must re-establish their settlements, especially in lifting promotion insights among students and benefactors. It is believed that education starts when one introduces the importance of something; in return, be inculcated successfully to their structure and will not depart from it. Academicians, on the one hand, are called to nurture the nature of research to augment patient care and outcomes. Such actions hold the potential to contribute ingenious policies and datum which are wanting to capitalize on decent maternal and child care. Furthermore, 
students must be exposed to research works, for it is only in that breadth information is reported. Data are garbage. It only becomes knowledge when processed.

COVID19, aside from its current aftermath, fabricates the likelihood to innovate to be something better in caring as the unending expression of nursing. Strengthening core networks and modifying district health centers decreases the maternal-child mortality and morbidity rates. Moreover, it enables the public to strengthen the virtue of resiliency and to withstand amidst crises and tests of times. 